may answer the purpose for others as it has now for some fimc answered mine.

Blencowe School, Cumberland, November 6

\section{Electric Motor Pendulum}

THE following very simple apparatus may I think be of use in any laboratory or other place where at times it is necessary to have a pendulum beating seconds in ordex to give the time for any experiments needing it.

It consists ol a Siemen.' galvanoscope, $A$, to which is attached the pendulum; the needle $\mathrm{N}$, preferably with platinuri contacts, works between two platinum wires, $B$ and $C$, with a small amount of play; these platinum wires are insulated from one another by being fastened into a piece of ebonite, which works on a pivot $D$. The needle is connected by its support to one end of the coil of the galvanoscope, the other end being to earth. To the wires, $\mathrm{B}$ and $\mathrm{C}$, are connected the opposite poles of a small battery, the centre of the battery being to earth.

The action of the instrument is as follows :-On slightly oscillating the pendulum the needle $N$ makes contact between $\mathrm{x}$ say, and the coil, the magnet being so arranged that the needie then deflects towards $\mathbf{B}$, thus carrying with it the movable contact wires until the pendulum reaches its limit of oscillation, when it

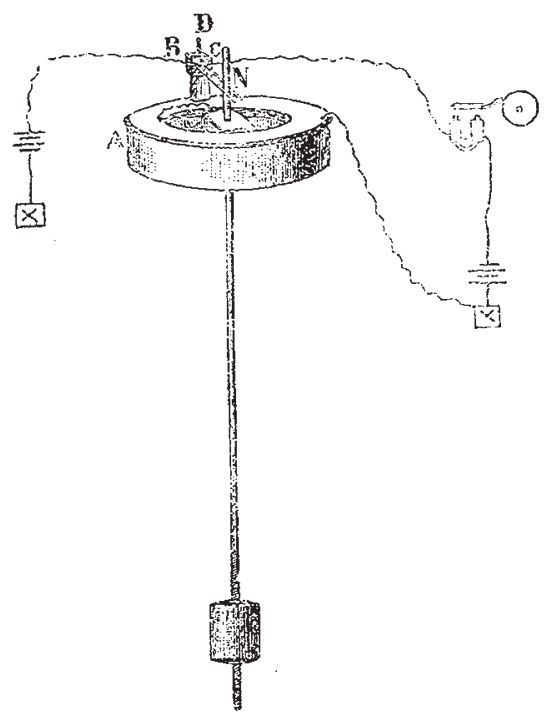

falls, breaks contact with $\mathrm{b}$ and makes contact with $c$, which thus tends to pull the reedle over to $\mathrm{C}$, and so on; in this way the pendulum receives at each oscillation the impulse necessary to overcome the forces tending to stop it; and thus will keep oscillating as long as the battery supplies the motive power. For small arcs the beat is not affecsed by ataliation in batiery pozer.

In the circuit of the battery we can intreduce an electromagnet which at each contact of the pendulum on one sids: will make a stroke on a bell, or indeed by a detent will move by a small train of wheels the hand's of a clock. If the pendulum is made to beat half seconds, then the contact being made alter. nately on each side, the bell stroke would beat seccnds. We could of course introduce any number of arrangements of this sort at any intervals along the circuit, and so move any number of clecks at oifferent positions in a large establishment, only one pendulum being requisite to control the whole set.

P. HigGs

\section{PROF. YOUNG ON THE SOLAR SPECTRUM}

THE paper of Prof. C. A. Young read at the last meeting of the American Association for the Advancement of Science describing his recent measures of the displacement of the $\mathrm{D}$ and other absorption lines at the receding and approaching limbs of the sun, has a double interest.
By careful measures to which all the necessary corrections have been rigorously applied, obtained by using a diffraction grating in combination with a prism, Prof. Young deduces from observation of the $D$ lines a value of $x .42 \pm 0.035$ miles per second for the simface velociiy of rotation at the sun's equator Direct observation of the motion of spots gives 125 miles per second, and the author thinks that the difference of these two values being so many times larger than the probable error of the spectroscopic method, the result of which agrees so well with Vogel's result, indicates that a portion of the displacement observed is produced by the difference in the angular velocity of rotation of the solax atmosphere which causes the absorption lines and the underlying luminous surface, and the sign of the difference would indicate that the atmosphere is swept forward with the greater velocity of the twro.

This conclusion is itself one of great interest, but fo: many persons the fact that it is based on the acceptance of Doppler's theory will be a source of satisfaction as indicating that the recent disputes as to its soundness are beginning to be considered settled and in its favour, as at any rate a near approximation to the truth.

One of its first assailants, on mathematical grounds, was Prof. Petzvall. But, as was pointed out by Mach in a "Contribution to Doppler'sTheory," published at Prague, in 1874 , his main argument fell beside the mark, while the only one which touched it went to prove that for comparatively small velocities of translation in the source of sound or light, compared to the velocity of wave transmission, Doppler's theory was a coriect approximation.

More recently Van der Willigen's mathematical objections have been apparently fairly disposed of by Mr. Christie, while the discrepancy that Father Secchi has lately pointed out betwe en the measures of displacement of spectral lines in the case of certain stars as observed by Mr. Huggins on the one hand and at Greenwich on the other, does not realiy affect Doppler's theory at al!, but only the degree of certainty with which it can be applied to the determination of stellar motion. But the facts are no as Father Secchi represents them. He points out, in a list of thinteen stars, that the displacement in the case of some five stars as observed by Huggins is in the opposite direction to that cbecrved at Greenwich. But the Greenwioh observations that he takes are some early tentative observations. We have taken the trouble to refer to the nost y cent Greenwich measures, and find that of the five disagrements insisted on only one hotds.

\section{INDIAN GEOLOGY}

THERE seems to be a very pretty quarrel just now-... and one urged with the usual absence of acrinuory in scientific controversies-as to the age or ages of an important group of rocks in Her Majesty's Indian empire.

For years it has been known that while a large mass of the rocks forming the Peninsula of India are unfossiliferous, there is also in that country an extensive series of beds the predominant, and frequently the only, fossils of which are vegetable remains. These beds were often spoken of as the Plant-beds of India. Among the flora certain forms which used to be called Paloosanice, now Ptilophyllum, were pretty generally distributed, while the genera Schizonoura and kalossopteris were found in lower portions of the series.

On the evidence of the first-named fossils and several others, a Jurassic age was assigned to the containing beds, while the identity of the Glossopteris with Australian forms involved these Indian beds in the dispute as to whether the coal-rocks of that country were likewise Jurassic or really carboniferous.

One portion of the Indian plant beds contained a limited terrestrial fauna which on high authority (Hux- 
ley) was considered probably Triassic. And another portion of this plant series (in Kutch) was found associated with a marine fauna ranging from the age of the Bath Oolite up to the Tithonian of Continental geologists.

On the whole question, the Triassic fossils, though their suggestiveness was admitted, were not considered sufficient to have much influence, and to the upper part of the plant-beds a Jurassic age was assigned, while the lower portion, apparently on the evidence of the Glossopteris, was thought to be Palæozoic, an opinion, however, which does not appear to have been universally received.

In this state, or one very similar, Dr. Feistmantel found the subject upon commencing his examination of the Indian fossil plants, aided by the separation of the series into several groups on stratigraphical grounds by the officers of the Geological Survey.

His examination has led to results so far as yet published, which will be found in two papers among the Recorlls of the Geological Survey (vol. ix., parts 2, 3).

From these it appears he considers the Kutch flora to represent a period in the Jurassic epoch somewhat earlier than that indicated by the associated marine fauna, so far as this has been examined, which is one of the points in debate, and that five of the upper divisions of the Indian plant beds (or Gondwana series) are Jurassic, while he contends that the remaining three of its lower groups are neither Jurassic nor Carboniferous, but Triassic.

In a paper immediately following Dr. Feistmantel's second contribution to the Records of the Indian Survey, Mr. W. T. Blanford discusses the whole question, and arrives at the conclusion that the evidence connecting the lower Indian plant beds with the Australian carboniferous rocks is about equal to that for their being of the same age as the Trias of Europe-pointing out that the land faunas and floras of Palæozoic and Mesozoic times differed from each other in different parts of the globe, at least as much as they do at present, and far more than the fauna of the sea. Also that the evidence founded upon fossil plants of the age of rocks in distant regions must be received with great caution, being certainly in same cases opposed to that furnished by the [contemporaneous] marine fauna.

In a coming volume of the "Pałæontologia Indica," Dr. Feistmantel will no doubt state his views and their reasons as fully as possible; meantime, enough has been said to show the interesting, yet rather difficult, nature of the subject, for more detail regarding which the papers just mentioned may be referred to.

\section{THE RIVER CLYDE}

THE profession of Civil Engineering, as defined by Telford, which definition is incorporated into the Charter of the Institution of Civil Engineers, is "the art of directing the great sources of power in Nature for the use and convenience of man," and there are few more striking examples of what science may do for commerce, or of what man may accomplish by working hand-in-hand with Nature than is the proud position of the River Clyde at the present day, as compared to what it was one hundred years ago, or even as late as the year 1840 .

To many of those who attended the recent meeting of the British Association, and who have fresh in their memory the geography of the City of Glasgow, with which must indissolubly be connected the princely hospitality of its inhabitants, it may be interesting to know that the noble river which has made Glasgow the mighty city that it is, from whose shores some of the largest ironclads of our fleet have been launched is a water highway, almost as much the work of man as is the Suez Canal itself.

One hundred years ago the Clyde was little more than a picturesque mountain-stream, so shallow, that at a place called Dumbuck Ford, twelve miles below Glasgow Bridge, passengers could traverse it on foot. Now, vessels drawing twenty-three feet of water can ride safely in the heart of the city at low water, and the largest ocean-going steamers can come up the river at all times of the tide.

This wonderful change has been brought about by a succession of engineering operations, in all of which Nature has been coaxed, by artificial means, into doing the largest share of the work; and the operations of man, great as they have been, have been directed solely to assist that work, and to remove obstacles which stood in its way. The names of the engineers under whose directions these improvements have been made, alone show that the highest scientific skill has been brought to bear upon the development of the water-way to the City of Glasgow; for, within the last 100 years, among the engineers who have been employed by the Clyde trustees, either to carry out improvements, or to prepare reports in connection therewith, will be found the names of Smeaton, Golborne, Watt, Sir John Rennie, Telford, Stevenson, Walker, Scott Russeli, and Bateman; but the largest engineering operations have been left for Mr. Deas, the present engineer of the Clyde navigation to carry out, for since the year 1872 greater progress has been made than during any previous equal period. In that time no less than 1,505 lineal yards of quayage have been added, slip and gravingdocks have been constructed, large cranes erected, and very considerable progress towards completion has been made in the celebrated Stobcross Docks of which we shall speak further on.

The exceptional construction of these docks, necessitated by the local peculiarities of the geological strata, formed the subject of a valuable paper read before the British Association by Mr. James Deas, C.E., under whose directions they are being constructed, and who has recently published a most interesting work upon the Clyde, illustrated with maps, sections, and tidal diagrams, and from which many of the data contained in this article have been derived, and to which we would refer those of our readers who wish for further investigation.

it is just a hundred and eight years ago since John Golborne, of Chester, visited the Clycle and macie his frst report, in which he pointed out that the shores of the river "in most places being much softer than the bottom, the current has operated there, because it could not penetrate the bed of the river, and has by those means gained in breadth what is wanting in depth ;" and, he added, "I shall proceed on these principles of assisting Nature when she cannot do her own work, by removing the stones and hard gravel from the bottom of the river where it is sha!low, and by contracting the channel where it is worn too wide."

Golborne, carrying these principles into practice, erected a number of rubble jetties so as to contract the channel, giving to the stream greater rapidity, and consequently greater scouring power, and by a system of dredging in the deeper shallows, and horse-ploughing in those which were exposed at low water, he loosened the hard crust forming the bed of the river, exposing to the action of the current the softer material below, which was speedily scoured away, and in less than eight years the depth of water at Dumbuck Ford was increased from 2 feet to F4 feet. Golborne was followed by Rennie, who, in I799, recommended the shortening of some of the jetties, the lengthening of others, and the construction of new ones, so as to direct the channel in its proper course with the least obstruction to the water ; and to insure this he recommended building rubble walls from point to point of the jetties, so as to avoid the formation of shoals between them. These suggestions were carried out by the Clyde

I "The River Clyde ; an Historical Description of the Rise and Progress of the Harbour of Glasgow." By James Deas, M. Inst.C.E. (Glasgow : James Mac!ehose, 1876 . 